\title{
Sedative load and frailty among community-dwelling population aged $\geq 65$ years
}

\author{
Abstract \\ Objective: To explore the association between use of sedative drugs and frailty. \\ Design: Cross-sectional study. \\ Setting: First wave of The Irish Longitudinal Study on Ageing (TILDA), a nationally \\ representative cohort of the community-dwelling population aged $\geq 50$ years in Ireland.
}

Participants: 1,642 men and 1,804 women aged $\geq 65$ years.

Measurements: Regular use of sedative drugs determined according to the sedative load model, frailty phenotype status and frailty deficit index (FI) score assessed using validated, established protocols.

Results: Overall, $19 \%$ of the participants took sedative drugs, most frequently hypnotics and antidepressants. Sedative drug use was at $46 \%$ for frail, $23 \%$ for prefrail and $9 \%$ for non-frail participants. After adjustment for covariates, sedative load was positively associated with being prefrail (OR=1.27; 95\% CI 1.11-1.46) and frail (OR=1.30; 95\% CI 1.02-1.64). Advancing age but not sex remained significant $(\mathrm{p}<0.001)$. After adjustment for covariates, the association between sedative load and the frailty deficit index (FI) was also significant at $p \leq 0.001$ ( $\beta=1.77$; 95\% CI 1.13-2.42).

Conclusion: Higher sedative load was positively associated with phenotype frailty and the frailty deficit index. This suggests that careful consideration must be given when prescribing sedatives to frail older adults, who are most vulnerable to adverse drug reactions and adverse health outcomes.

Running title: Sedative load and frailty in older adults Key words: sedative load, frailty, drug utilisation, ageing, frailty index 
Older people are susceptible to adverse drug events owing to the diminishing physiological reserve associated with ageing. ${ }^{1}$ This can be exacerbated further by acute or chronic diseases and by the drugs used to treat them..$^{2}$ Older populations are often prescribed a range of drugs with sedative properties (e.g. psychotropics). ${ }^{3}$ Sedation is defined as subjective feelings of drowsiness and sleepiness, but also as decreased psychomotor functioning, which can be measured in objective tests. ${ }^{4}$ Sedative drugs have been associated with falls, fractures, physical and cognitive impairment and disability among community-dwelling older people. $3,5,6,7$

With more drugs being taken concomitantly, the risk of interactions and cumulative sedative effects is increased ${ }^{1,8,9}$, leading to the development of different models to study the sedative effect of drugs. ${ }^{10}$ The "sedative load model" was developed to quantify the cumulative effect of taking multiple drugs with sedative properties. ${ }^{11}$ Older age, female sex, lower education levels, impaired mobility depression and dementia are predictors of sedative load exposure. 3,8 becoming an increasing challenge. Frailty develops as a consequence of age-related declines in many physiological systems, resulting in vulnerability to stressors (e.g. infection or hospitalisation) and adverse health outcomes. ${ }^{12}$ Fried et al. ${ }^{13}$ characterised frailty as a clinical phenotype of at least three of five indicators: unintentional weight loss, slow walking speed, self-reported exhaustion, low levels of activity and muscle weakness. Frail individuals are at increased risk of falls, hospitalisation, worsening mobility, disability and death. ${ }^{12}$ Frailty has also been linked to impaired global cognition and cognitive decline. ${ }^{14,15}$ Using a different approach, Rockwood et al. ${ }^{16}$ have also characterised frailty, as an age-associated, non-specific accumulation of deficits resulting in vulnerability to stressors and adverse outcomes. They present this accumulation of deficits as an index score called the frailty deficit index (FI).

Frail older adults are more susceptible to age- and disease-related changes in their pharmacokinetic and pharmacodynamic responses to drugs. ${ }^{2,17}$ This is compounded further as frail individuals are more likely to be administered several medications, resulting in polypharmacy..17,18 
poorer physical performance, balance and mobility. ${ }^{19,20}$ In contrast, higher sedative load was not associated with poorer physical or cognitive performance, but was associated with impairments in activities of daily living (ADLs) and Instrumental ADLs (IADLs) among community-dwelling older men in Australia. ${ }^{8}$ Data regarding the direct association of sedative load and frailty has not been published.

In this study we assessed the potential relationship between sedative load exposure (independent variable) and frailty (dependent variable) measured using the phenotype and deficit index definitions.

\section{METHODS}

\section{Study population}

Cross-sectional analyses were performed using data from the first wave of The Irish Longitudinal Study on Ageing (TILDA) conducted between 2010-2011. The TILDA study cohort includes 8,175 participants representative of the community-living population aged 50 and older living in Ireland. Households were selected in geographic clusters from a list of all Irish residential addresses. Each household was visited by an interviewer and any resident aged 50 or older as well as their spouse or partner was invited to participate. The household response rate was $62.0 \%$. Ethical approval was obtained from the Trinity College Dublin Research Ethics Committee and all participants provided written informed consent. Those with cognitive impairment that prevented consent being given were not included in the study for ethical reasons. Participants were interviewed in their homes and answered questions on health, social interactions, and financial circumstances. Each participant was invited to travel to a health centre for a comprehensive health assessment. The sampling procedure, the home interview, and the health assessment have been described in detail previously. ${ }^{21}$ From the total sample of 8,175 participants, 3,446 aged 65 and older provided details of their regular medication use (Tables 1 and 2). Of these, 1,718 participants attended the health centre assessment and provided sufficient data to assess their frailty status (Table

\section{3).Assessment of sedative load (SL) score}


The in-home inventory of drugs and food supplements was conducted by asking the question "Now I would like to record all medications that you take on a regular basis, like every day or every week. This will include prescription and non-prescription medications, over-the-counter medicines, vitamins, and herbal and alternative medicines." No information about dose, frequency, quantity or prescription status was obtained.

Drugs were coded using the ATC (Anatomical-Therapeutic-Chemical) classification system $^{22}$ and the effect of taking multiple drugs with sedative properties was calculated using the sedative load model.311 Drugs were categorized as: primary sedatives e.g. anxiolytics (Group 1); drugs with a sedating component or side effect e.g. selective serotonin reuptake inhibitors (Group 2); drugs with sedation as a potential adverse reaction e.g. acetylcholinesterase inhibitors (Group 3); all other medicines with no known sedative properties (Group 4). Drugs included in groups 1,2 and 3-4 were assigned sedative ratings of 2, 1 (Table 2) and 0 respectively. Sedative load was calculated as the sum of the sedative ratings at an individual level, for regularly used drugs. Sedative Load (SL) scores of 0, 1-2 and 3 indicated no, low and high sedative load respectively.

The sedative load model was first published in 2003 and was updated in 2011.3,11 In our study, this model was assessed and modified to include drugs taken by participants in this study and to reflect the current knowledge about sedative effects of drugs. Two experienced clinical pharmacists $(\mathrm{IM}, \mathrm{JP})$ independently consulted, reviewed and amended scores for the original updated list of drugs ${ }^{11}$ using standard and widely accepted reference sources e.g. product characteristics (SmPC) information, and Maudsley Prescribing Guidelines ${ }^{23}$. Relevant MEDLINE articles ${ }^{24-26}$ informed the scoring of drugs not included on the list. Scores were reviewed by an experienced psychogeriatrician and disagreements were resolved by consensus. Drugs included in our analysis with respective scoring are listed in Table 2.

\section{Frailty Measures}

Phenotype frailty was operationalized using population-specific cut-points following the methodology of Fried and colleagues ${ }^{13}$. This was done owing to differences in the assessments of 
weakness (sex- and bmi-adjusted grip-strength measured using baseline dynamometer), physical activity (sex-adjusted kilocalories (kcals) from the International Physical Activity QuestionnaireShort Form [IPAQ-SF]), and walking speed (sex- and height-adjusted $\mathrm{cm} / \mathrm{s}$ using the GAITRite portable walkway) that made using the absolute cut-points reported by Fried and colleagues inappropriate. Weight loss was ascertained by the question "In the past year have you lost 10 pounds $(4.5 \mathrm{~kg})$ or more in weight when you were not trying to." Exhaustion was captured using two items from the 20-item Centre for Epidemiological Studies Depression (CES-D) scale. Participants were asked how often they felt that "I could not get going" and "I felt that everything I did was an effort". A response of "moderate amount/all of the time" to either question was considered as "exhaustion." The presence of $0,1-2$ and $\geq 3$ of the five criteria classified participants as non-frail, prefrail (an intermediate state) and frail, respectively. The operationalization of the frailty phenotype in the TILDA cohort at Wave 1 has been described previously.27,28

\section{Demographic, Health and Lifestyle Measures}

Demographics included age, sex, education (reference group: secondary/higher) and marital status. The health measures recorded were: self-rated health (Ecellent/Very good/Good/Fair/ Poor); disability (the inability to perform one or more Instrumental/Activities of Daily Living (IADL or ADL)) ${ }^{30,31}$; falls ( $\geq 1$ self-reported fall in the past year); the number of chronic diseases or conditions (recorded as self-reported physician's diagnosis of heart attack, heart failure, angina, hypertension, high cholesterol, stroke, diabetes, lung disease, asthma, arthritis and osteoporosis); the number of all medications taken regularly (excluding supplements); underweight (BMI <18.5); obese (BMI $\geq 30$ ); self-reported difficulty sleeping; cognitive impairment 
141 (MMSE - Mini mental state exam score $\leq 24)^{32}$; self-rated memory; depressive symptoms (CES-D -

142 The Center for Epidemiologic Studies Depression Scale score $\geq 16)^{33}$; anxiety (HADS-A - Hospital 143 Anxiety and Depression Scale - Anxiety score $\geq 11$ ) and loneliness. Life-style factors included 144 alcohol consumption (defined as a yes/no response to the question "Do you drink alcohol?") and present time?”).

Statistical analyses

Demographic, health and lifestyle measures were presented as means and standard deviations or counts and percentages. Comparisons across different SL and frailty groups were conducted using chi-square test for categorical variables and analysis of variance (ANOVA) for continuous variables including SL score and FI score. group: non-frail).

scores. Unstandardized regression coefficients (B) with $95 \%$ CI were measured with accompanying p-values. Analyses were adjusted for the same covariates listed above. Analyses were performed using SPSS 18 (SPSS for Windows Release 18.0).

\section{RESULTS}

\section{Characteristics of the study population and sedative load (SL)}

Mean (SD) age was $73.0( \pm 6.4)$ years, ranging from 65 to 99 years and $52.4 \%$ were female. 
by $668(19.4 \%)$ participants. Mean (SD) sedative load was 0.41 ( \pm 1.00 ; range 0 to 9$)$. Sedative load was higher in women $(0.50[ \pm 1.09], \mathrm{p} \leq 0.001)$, than in men $(0.32[ \pm 0.88])$ and highest in the $75-84$ years group $(0.51 \pm 1.11)$ compared to those aged $65-74$ years $(0.36 \pm 0.93)$ or $\geq 85$ years, $(0.48$ \pm 0.97 ) respectively; $p \leq 0.001$. Detailed characteristics of this cohort by SL are provided in Table 1 .

The most frequently used primary sedatives (Group 1) were hypnotics (ATC N05C), and drugs most used with sedation as a prominent side effect (Group 2) were SSRIs (ATC N06AB) within antidepressants. Cohort SL score was 1,421. Hypnotics (ATC N05C) were the major contributor with an overall SL score of 450 ahead of antidepressants (ATC N06) with an overall SL score of 350. Details of sedative drug use are provided in Table 2.

\section{Prevalence of frailty}

Of the 3,446 participants, 1,718 attended the health centre assessment and provided sufficient data to assess their frailty status. The prevalence of frailty in this sample was $4.2 \%$ ( $n=72), 39.1 \%(n=672)$ were prefrail and 56.7\% (n=974) were non-frail. Frail participants were significantly older, had more chronic diseases, poorer education and more I/ADL disability. They had significantly higher drug use, polypharmacy ( $5 \geq$ drugs) and sedative drugs use. Prefrail participants were an intermediate group performing significantly worse on these measures compared with the non-frail group but significantly better than the frail group. Sedative drug use was at $46 \%$ for frail, $23 \%$ for prefrail and $9 \%$ for non-frail participants. More women were prefrail or frail, but not significantly so. Mean FI score increased with frailty status through all three categories (Table 3 and Figure 1).

\section{The relationship between frailty and sedative load (SL)}

Mean SL was independently associated with frailty using both the frailty phenotype and FI models as shown in (Figure 1. In unadjusted analyses, frail (OR 2.08, 95\%CI 1.70-2.54) and prefrail (OR 1.63, 95\%CI 1.43-1.86) participants were significantly more likely to use medicines with sedative properties than non-frail participants. After adjustment for all listed variables in Table 1, frailty (OR 1.30, 95\%CI 1.02-1.64; $\mathrm{p}=0.023$ ) and prefrailty (OR 1.27, 95\%CI 1.11-1.46; $\mathrm{p}<0.001$ ) 
remained significantly associated with SL score.

Multiple regression analysis was used to independently test if the SL was significantly correlated with FI score. In unadjusted analyses higher FI scores were associated with higher SL cores $(\beta=0.30 ; \mathrm{p}<0.001$. $\mathrm{B}=2.54 ; 95 \%$ CI $2.15-2.92)$. The adjusted model for all covariates listed in Table 1, explained $10.4 \%$ of the variance $\left(\mathrm{R}^{2}=0.104, \mathrm{~F}(10.72)=124.64, \mathrm{p} \leq 0.001\right)$ and the association between SL and the FI score was significant at $\mathrm{p} \leq 0.001$ (B=1.77; 95\% CI 1.13-2.42).

Respondents who did not provide data on frailty status $(n=1,728)$ were more likely to be older, less educated, took more medicines and had a higher SL at $\mathrm{p}<0.05$. There was no difference in sex or number of comorbidites reported between both groups.

\section{DISCUSSION}

This was the first study to investigate the association between SL and frailty in communitydwelling adults aged 65+ years. Our data indicates the use of sedative drugs was positively associated with being both prefrail and frail in unadjusted and adjusted analyses using two established methodologies to assess frailty, phenotype frailty and the FI.

Our findings revealed that one in five participants in our study took at least one sedative drug, which falls between the Australian and Finnish studies where $15 \%$ and 29\% of participants reported sedative drug use, respectively. 3,8 These differences may emerge from age/sex characteristics of the populations studied, their cultural background, environmental differences and doctors' prescribing habits. Those who reported higher SL in our study had poorer health in line with previous studies. ${ }^{3,8}$ The drugs which contributed most to SL in our study were hypnotics (Group 1) and SSRIs with other antidepressants (Group 2). This is similar to the Finnish study3 but differs from the Australian study ${ }^{8}$, where anxiolytics (Group 1) and antidepressants (Group 2) were the major contributors to overall SL. We updated the original Finnish model to reflect current knowledge regarding the sedative effect, as available from standard reference sources. The majority of changes involved re-scoring between Groups 1 to 2, and only lithium moved between the categories of SL and no SL. We believe the modified model better reflects the sedative burden 
of reported drugs and both the original and modified models of SL were significantly associated with frailty (Appendices 1 and 2).

Frail participants in our cohort were older and had poorer health indicators, characteristic of frailty in other studies. ${ }^{12,13}$ Moreover, the respective exposure of frail and prefrail participants to sedative drugs was five and three times higher compared to their non-frail counterparts. Adjusting for relevant confounders, SL was significantly associated with both frailty and prefrailty. For each increase in SL score, the likelihood of being frail or prefrail increased by $30 \%$ and $27 \%$, respectively. While a clear age gradient existed, there was no sex difference detected in our sample despite reports that females are more likely to be frail.. ${ }^{33,34}$ SL was also significantly associated with higher FI score.

Loss of muscle mass and function (sarcopenia) is a marker of frailty and may be influencing the association between SL and frailty. Similarly, it is known that a decrease in lower limb muscle mass, strength and function leads to poorer gait and mobility. ${ }^{35}$ Thus, the association between SL and frailty may be explained by the adverse impact of sedative exposure on physical function, superimposed on a sarcopenia-related frailty process. These findings could have important clinical implications with respect to prevention of other adverse health outcomes such as falls, fractures and disability. These adverse outcomes are common among older adults, result from both sedative drug use and frailty and constitute a significant burden to healthcare systems worldwide. 12,13,36,37 This suggests that minimising sedative exposure in prefrail and frail older adults may be clinically significant given their increased vulnerability to adverse drug reactions and adverse health outcomes. Longitudinal and intervention studies with measures of sarcopenia, frailty and SL may help to better inform these relationships. Indeed additional future waves of the TILDA study will contribute to our understanding of the impact of increasing sedative load exposure among the prefrail and frail.

Polypharmacy, high-risk treatment regimens and the Drug Burden Index (an alternate tool to the SL model) were previously associated with frailty at baseline and incident frailty after 2years. ${ }^{18,38}$ However, the strengths of our study included the use of a large sample, that was very well characterised using a broad range of epidemiologically and clinically validated measures. Also, 
the association between SL and frailty was confirmed using two independent and methodologically different measures of capturing frailty, lending additional support to the relationship between SL and frailty. Furthermore, medication data was collected by trained interviewers in the home reducing self-report recall bias. ${ }^{39}$. Few methods exist to measure the burden of sedative drugs but the advantages of the SL model are three-fold: It includes drugs with sedative properties prescribed for somatic diseases, it describes cumulative exposure to drugs exerting sedative effects through multiple mechanisms in the CNS, and it incorporates a sedative rating for each drug. 3,8,19,20,

There were some limitations of the study. The SL model has not been validated against in vitro or in vivo measures of sedative activity, or objective tests of altered psychomotor functioning. Drug dosage and frequency were not recorded. Only regularly taken drugs were included, not those taken 'when required' (prn). There may also be some limitation in terms of generalising findings in relation to the SL model, due to variations in the prescribing patterns of different countries and healthcare systems. To provide wider generalizability of these study findings, similar research using the same sedative load protocol should be replicated in different population. The necessity to collect objective measurements of grip strength and walking speed in order to measure the frailty phenotype status is also a potential limitation. While objective measures are considered more reliable than self-report measures, they are often less feasible, particularly in a clinical setting. Indeed participants in this study who did not perform a health assessment, could not be assessed for frailty, although they were older, took more drugs, and had a higher SL. Similarly, individuals with cognitive impairment that prevented informed consent, and are likely to be frail, were also excluded from this study. This suggests that our estimation of the association between sedatives and frailty may be conservative. Finally, cross-sectional data do not allow assessment of the causality of the relationship between frailty and SL. Some of these limitations will be overcome during subsequent waves of this longitudinal study of ageing.

\section{CONCLUSIONS}

The use of drugs with sedative properties in older Irish adults is significant and more prevalent in the subpopulation with the poorest health status. In this study, two models of frailty 
were associated with higher SL. As frail, and prefrail, people are more susceptible to adverse responses to drugs and adverse health outcomes, additional consideration when choosing appropriate sedative drugs is needed in this vulnerable group. However, further studies are needed to assess the impact over time of greater sedative use among prefrail and frail older adults.

\section{ACKNOWLEDGEMENTS}

Support for this study was provided by Irish Life (Grant No D02155), Atlantic Philanthropies (D02175), and the Irish Government Department of Health and Children (G01529).

The authors would like to acknowledge the participants in the study, the members of the TILDA research team, the study nurses, and administrators.

Authors would specially like to thank Professor Brian Lawlor, MD of Department of Psychiatry, Trinity College Dublin, Ireland for his help in reviewing independently the sedative load categorisation.

\section{CONFLICT OF INTEREST}

The authors declared no conflict of interest.

\section{AUTHOR CONTRIBUTIONS}

Mr. Peklar and all co-authors take responsibility for the integrity of the data and the accuracy of the data analysis. Mr. Peklar: wrote manuscript, designed and performed research, analysed data. Dr. O'Halloran: wrote manuscript, performed research, analysed data. Dr. Maidment: designed research, analysed data Dr. Henman: designed and performed research. Professor Kenny: designed research. Dr. Kos: designed and performed research.

\section{REFERENCES}

1 Mallet L, Spinewine A, Huang A. The challenge of managing drug interactions in elderly people. Lancet. 2007 Jul 14;370(9582):185-91.

2 McLachlan AJ, Pont LG. Drug metabolism in older people - a key consideration in achieving optimal outcomes with medicines. J Gerontol A Biol Sci Med Sci. 2012 February;67A(2): 175-180.

3 Taipale HT, Bell JS, Uusi-Kokko M et al. Sedative load among community-dwelling people aged 75 years and older. Drugs Aging 2011;28(11):1-13.

4 Bourin M, Briley M. Sedation, an unpleasant, undesirable and potentially dangerous side-effect of many psychotropic drugs. Hum Psychopharmacol Clin Exp 2004; 19: 135-139.

5 What's to blame for falls and fractures? Poor sleep or the sleeping medication?: Comment on 
"Nonbenzodiazepine sleep medication use and hip fractures in nursing home residents".

Widera E. JAMA Intern Med. 2013 May 13;173(9):761-2.

6 Hanlon JT, Horner RD, Schmader KE et al. Benzodiazepine use and cognitive function among communitydwelling elderly. Clin Pharmacol Ther. 1998 Dec;64(6):684-92.

7 Gray SL, LaCroix AZ, Hanlon JT et al. Benzodiazepine use and physical disability in community-dwelling older adults. J Am Geriatr Soc. 2006 Feb;54(2):224-30.

8 Gnjidic D, Le Counteur DG, Hilmer SN et al. Sedative load and functional outcomes in community-dwelling older Australian men: the CHAMP study. Fundam Clin Pharmacol.2014 Feb:28(1):10-9..

9 Hilmer SN, Gnjidic D. The effect of polypharmacy in older adults. Clin Pharmacol Ther. 2009 Jan;85(1):86-8.

10 Taipale HT, Hartikainen S, Bell JS. A comparison of four methods to quantify the cumulative effect of taking multiple drugs with sedative properties. Am J Geriatr Pharmacother. 2010;8:460-471.

11 Linjakumpu T, Hartikainen S, Klaukka T et al. A model to classify the sedative load of drugs. Int J Geriatr Psychiatry. 2003 Jun;18(6):542-4.

12 Clegg, A, Young J, Iliffe S et al. Frailty in elderly people. Lancet 2013; 381: 752-62.

13 Fried LP, Tangen CM, Walston J et al. Frailty in Older Adults: Evidence for a Phenotype. J Gerontol A Biol Sci Med Sci. 2001 Mar;56(3):M146-56.

14 Robertson DA, Savva GM, Kenny RA. Frailty and cognitive impairment-A review of the evidence and causal mechanisms. Ageing Res Rev. 2013 Jul 4;12(4):840-851.

15 Avila-Funes JA, Amieva H, Barberger-Gateau P et al. Cognitive impairment improves the predictive validity of the phenotype of frailty for adverse health outcomes: the three-city study. J Am Geriatr Soc. 2009 Mar;57(3):453-61.

16 Rockwood K, Mitnitski A. Frailty in relation to the accumulation of deficits. J Gerontol A Biol Sci Med Sci. 2007 Jul;62(7):722-7. Review.

17 Hubbard RE, O’Mahony MS, Woodhouse KW. Medication prescribing in frail older people. Eur J Clin Pharmacol. 2013 Mar;69(3):319-26.

18 Gnjidic D, Hilmer SN, Blyth FM et al. High-risk prescribing and incidence of frailty among older community-dwelling men. Clin Pharmacol Ther. 2012 Mar;91(3):521-8.

19 Taipale HT, Bell JS, Gnjidic D et al. Muscle strength and sedative load in community-dwelling people aged 75 years and older: a population-based study. J. Gerontol. A Biol. Sci. Med. Sci. (2011) 66 1384-92.

20 Taipale HT, Bell JS, Gnjidic D et al. Sedative load among community -dwelling people aged 75 years and older: association with balance and mobility. J. Clin. Psychopharmacol. (2012) 32 218-224.

21 Kearney PM, Cronin H, O'Regan C et al. Cohort profile: the Irish Longitudinal Study on Ageing. Int J Epidemiol. 2011;40:877-884.

22 WHO Collaborating Centre for Drug Statistics Methodology (www.whocc.no/atc) (accessed on 25/09/2013).

23 Taylor D (ed). The Maudsley Prescribing Guidelines in Psychiatry, 11th Ed. Wiley-Blackwell 2012.

24 Leucht S, Cipriani A, Spineli L et al. Comparative efficacy and tolerability of 15 antipsychotic drugs in schizophrenia: a multiple-treatments meta-analysis. Lancet 2013;382(9896):951-62

25 Gao K, Ganocy SJ, Gajwani P et al. J Clin Psychiatry. 2008 Feb;69(2):302-9. A review of sensitivity and tolerability of antipsychotics in patients with bipolar disorder or schizophrenia: focus on somnolence. 
26 Ananth J, Parameswaran S, Gunatilake S. Side effects of atypical antipsychotic drugs. Curr Pharm Des. 2004;10(18):2219-29,

27 O'Halloran AM, Finucane C, Savva GM et al. Sustained Attention and Frailty in the Older Adult Population. J Gerontol B Psychol Sci Soc Sci 2013: doi:10.1093/geronb/gbt009.

28 Savva GM, Donoghue OA, Horgan F et al... Using timed up-and-go to identify frail members of the older population. J Gerontol A Biol Sci Med Sci. 2013 Apr;68(4):441-6.

29 Searle S, Mitnitski A, Gahbauer E et al. A standard procedure for creating a frailty index. BMC Geriatr 2008, $8: 24$.

30 Katz S, Ford AB, Moskowitz RW et al. 24 Studies of Illness in the Aged. The Index of ADL: A Standardized Measure of Biological and Psychosocial Function. JAMA. 1963;185(12):914-919.

31 Lawton, M.P., \& Brody, E.M. (1969). Assessment of older people: Self-maintaining and instrumental activities of daily living. The Gerontologist,9(3), 179-186.

32 Folstein MF, Folstein SE, McHugh PR; "Mini-mental state". A practical method for grading the cognitive state of patients for the clinician. J Psychiatr Res. 1975 Nov;12(3):189-98.

33 Orme JG, Reis J, Herz EJ. Factorial and discriminant validity of the Center for Epidemiological Studies Depression (CES-D) scale. J Clin Psychol. 1986 Jan;42(1):28-33.

34 Collard RM, Boter H, Schoevers RA et al. Prevalence of frailty in community-dwelling older persons: a systematic review. J Am Geriatr Soc 2012; 60: 1487-92.

35 Wolfson L, Judge J, Whipple R et al. Strength is a major factor in balance, gait, and the occurrence of falls. J Gerontol A Biol Sci Med Sci. 1995 Nov;50 Spec No:64-7.

36 Morley JE, Malmstrom TK, Miller DK. A simple frailty questionnaire (RAIL) predicts outcomes in middle aged Aferican Americans. J Nutr Health Aging. 2012 Jul;16(7):601-8.

37 Woo J, Leung J, Morley JE.. Comparison of frailty indicators based on clinical phenotype and the multiple deficit approach in predicting mortality and physical limitation. J Am Geriatr Soc. 2012 Aug;60(8):1478-86.

38 Hilmer SN, Mager DE, Simonsick EM et al. A drug burden index to define the functional burden of medications in older people. Arch Intern Med 2007;167:781-7.

39 Qato DM, Schumm LP, Johnson M et al. Medication data collection and coding in a home-based survey of older adults. Journals of Gerontology Series B: Psychological Sciences and Social Sciences 2009;64B(S1):i86-93. 


\begin{tabular}{|c|c|c|c|c|c|}
\hline & \multirow{3}{*}{$\begin{array}{c}\begin{array}{c}\text { Total } \\
\text { Population }\end{array} \\
(n=3,446) \\
{[n(\%)]}\end{array}$} & \multicolumn{4}{|c|}{ Sedative Load [n(\%)] } \\
\hline & & $(n=2,778)$ & $(n=495)$ & $(n=173)$ & Р-уаalu \\
\hline & & $\mathbf{0}$ & 1 or 2 & $\geq 3$ & \\
\hline \multirow[t]{3}{*}{ Age (Yrs) } & $2,137(62.0)$ & $1,771(82.9)$ & $279(13.1)$ & $87(4.1)$ & \\
\hline & $1,091(31.7)$ & $843(77.3)$ & $172(15.8)$ & $76(7.0)$ & $<0.001$ \\
\hline & $218(6.3)$ & $164(75.2)$ & $44(20.2)$ & $10(4.6)$ & \\
\hline Sex (Female) & $1,804(52.4)$ & $1,387(49.9)$ & $310(62.6)$ & $107(61.8)$ & $<0.001$ \\
\hline Education (None/primary) & $1,514(44.0)$ & $1,175(42.3)$ & $255(51.5)$ & $84(48.6)$ & $<0.001$ \\
\hline Married & $2,034(59.0)$ & $1,708(61.5)$ & $245(49.5)$ & $81(46.8)$ & $<0.001$ \\
\hline Alcohol users & $1,822(63.1)$ & $1,516(64.8)$ & $228(55.9)$ & $78(55.7)$ & 0.001 \\
\hline Currently smoking & $469(13.6)$ & 357 (12.9) & $78(15.8)$ & $34(19.7)$ & 0.011 \\
\hline No. of chronic conditions (Mean, SD) & $2.21(1.54)$ & $2.06(1.46)$ & $2.76(1.64)$ & $3.06(1.87)$ & $<0.001$ \\
\hline Self rated health (Fair/Poor) & $564(16.4)$ & $348(12.5)$ & $152(30.8)$ & $64(37.0)$ & $<0.001$ \\
\hline No. of drugs (Mean, SD) & $3.33(2.71)$ & $2.79(2.39)$ & $5.16(2.60)$ & $6.86(3.04)$ & $<0.001$ \\
\hline IADL disability ( $\geq 1$ disability) & $170(4.9)$ & $121(4.4)$ & $37(7.5)$ & $12(6.9)$ & $<0.001$ \\
\hline ADL disability ( $\geq 1$ disability) & $431(12.5)$ & $262(9.4)$ & $111(22.4)$ & $58(33.5)$ & $<0.001$ \\
\hline Self rated memory (Fair/Poor) & $705(20.5)$ & $487(17.5)$ & $153(30.9)$ & $65(37.6)$ & $<0.001$ \\
\hline COPD/Asthma & $440(12.8)$ & $319(11.5)$ & $85(17.2)$ & $36(20.8)$ & $<0.001$ \\
\hline MCI/Dementia (MMSE score $\leq 24$ ) & $245(10.5)$ & $175(9.2)$ & $50(15.5)$ & $20(15.7)$ & $<0.001$ \\
\hline CVD & $1,993(57.8)$ & $1,559(56.1)$ & $319(64.4)$ & $115(66.5)$ & $<0.001$ \\
\hline Arthritis & $1,304(37.8)$ & $960(34.6)$ & $241(48.7)$ & $103(59.5)$ & $<0.001$ \\
\hline Stroke & $95(2.8)$ & $53(1.9)$ & $25(5.1)$ & $17(9.8)$ & $<0.001$ \\
\hline Diabetes & $365(10.6)$ & $276(9.9)$ & $68(13.7)$ & $21(12.1)$ & 0.032 \\
\hline Depression (CES-D score $\geq 16$ ) & $282(8.4)$ & $165(6.0)$ & $77(16.0)$ & $40(24.1)$ & $<0.001$ \\
\hline Anxiety (HADS-A score $\geq 11$ ) & $245(9.0)$ & $157(7.1)$ & $57(15.2)$ & $31(23.7)$ & $<0.001$ \\
\hline Chronic pain (Moderate/severe) & $903(26.2)$ & $591(21.3)$ & $220(44.5)$ & $92(53.2)$ & $<0.001$ \\
\hline Difficulty sleeping (Most of the time) & $383(11.1)$ & $245(8.8)$ & $91(18.4)$ & $47(27.2)$ & $<0.001$ \\
\hline Falls ( $\geq 1$ in past year) & $754(21.9)$ & $551(19.8)$ & $137(27.7)$ & $66(38.2)$ & $<0.001$ \\
\hline $\begin{array}{l}\text { Loneliness } \\
\text { (moderate/most of the time) }\end{array}$ & $285(8.3)$ & $190(6.8)$ & $62(12.5)$ & $33(19.2)$ & $<0.001$ \\
\hline
\end{tabular}

I/ADL - Instrumental/Activities of Daily Living.

COPD - Chronic Obstructive Pulmonary Disease.

MCI - Mild Cognitive Impairment.

MMSE - Mini Mental State Examination

CVD - Cardiovscular disease (high blood pressure, atrial fibrillation, transient ischemic attack).

CES-D - Center for Epidemiological Studies -Depression scale. 


\begin{tabular}{|c|c|c|c|c|}
\hline Group & ATC & INN Reported by Participants & $\mathbf{N}$ & $\%$ \\
\hline Antidepressants & N06A & $\begin{array}{l}\text { clomipramine }^{\#} \text {, trimipramine } \\
\text { amitriptyline } \text { lofepramine }^{\#} \text {, dothiepin } \\
\text {, fluoxetine, } \\
\text { citalopram, paroxetine, sertraline, } \\
\text { escitalopram, trazodone } \\
\text { venlafaxine, mirtazapine }{ }^{\#} \text {, } \\
\text { vuloxetine }\end{array}$ & 265 & $7.7 \%$ \\
\hline Hypnotics & N05C & $\begin{array}{l}\text { flurazepam\#, nitrazepam\#, flunitrazepam", } \\
\text { lormetazepam\#, temazepam\#, zopiclon\#, } \\
\text { zolpidem", zaleplon" }\end{array}$ & 223 & $6.5 \%$ \\
\hline Opioid analgesics & N02A & $\begin{array}{l}\text { morphine, oxycodone, dihydrocodeine, } \\
\text { codeine (also combinations), fentanyl, } \\
\text { dextropropoxyphene, buprenorphine, } \\
\text { tramadol (also combinations), meptazinol }\end{array}$ & 133 & $3.9 \%$ \\
\hline Antie & 03 & $\begin{array}{l}\text { phenobarbital\#, primidone, phenytoin, } \\
\text { clonazepam\#, carbamazepine, valproic acid, } \\
\text { tiagabine, lamotrigine, gabapentin", }\end{array}$ & 125 & $360 \%$ \\
\hline & & $\begin{array}{l}\text { levetiracetam, pregabalın } \\
\text { diazepam }^{\#}, \text { chlordiazepoxide }^{\#}, \text { lorazepam }^{\#}, \\
\text { bromazepam }^{\#} \text {, clobazam }\end{array}$ & 125 & $3.6 \%$ \\
\hline Anxiolytics & N05B & alprazolam\# & 88 & $2.6 \%$ \\
\hline $\begin{array}{l}\text { Antipsychotics (both } \\
\text { conventional\&atypical) }\end{array}$ & N05A & $\begin{array}{c}\text { chlorpromazine }{ }^{\#}, \text { prochlorperazine }{ }^{\#} \text {, } \\
\text { sulpiride, olanzapine } e^{\#} \text {, quetiapine }{ }^{\#} \text {, } \\
\text { risperidone }\end{array}$ & 42 & $1.2 \%$ \\
\hline Propulsives & A03FA & Domperidone & 21 & $0.6 \%$ \\
\hline Anti-Parkinson Drugs & N04 & biperiden, ropinirole, pramipexole, rotigotine & 12 & $0.3 \%$ \\
\hline Muscle relaxants & M03BX & baclofen, tizanidine & 6 & $0.2 \%$ \\
\hline & & clonidine, cinnarizine, zolmitriptan, valerian & & \\
\hline Other & & extract $\#$ & 8 & $0.2 \%$ \\
\hline Opioid antitussives & R05DA & codeine, dextromethorphan, dihydrocodeine & 4 & $0.1 \%$ \\
\hline Antihistamine & R06 & chlorphenamine, promethazine ${ }^{\#}$ & 3 & $0.1 \%$ \\
\hline $\begin{array}{l}\text { No of respondents } \\
\text { reporting at least one } \\
\text { drug with } S L \geq 1\end{array}$ & & & 668 & $19.4 \%$ \\
\hline
\end{tabular}

\# Drug is included in "group 1" (SL score 2) 
445

446

447

448

Table 3. Modified Sedative load, and participant characteristics, by frailty phenotype status $(n=1,718)$

\begin{tabular}{|c|c|c|c|}
\hline \multirow[t]{2}{*}{ Independent Variables } & \multicolumn{3}{|c|}{ Frailty Phenotype Status } \\
\hline & $\begin{array}{c}\text { Robust } \\
974(56.7)\end{array}$ & $\begin{array}{c}\text { Prefrail } \\
672(39.1)\end{array}$ & $\begin{array}{c}\text { Frail } \\
72(4.2)\end{array}$ \\
\hline Frailty Index (FI) score (Mean, SD) & $0.11(0.08)$ & $0.18(0.11)^{* *}$ & $0.32(0.12)^{* *}$ \\
\hline Exposure to sedative drugs ( $S L \geq 1$ ) & $84(8.6)$ & $153(22.8)^{* *}$ & $33(45.8)^{* *}$ \\
\hline Sedative load score (Mean, SD) & $0.17(0.65)$ & $0.50(1.05)^{* *}$ & $0.89(1.22)^{* *}$ \\
\hline Age (Mean, SD) & $70.12(4.44)$ & $72.45(5.56)^{* *}$ & $76.17(6.59)^{* *}$ \\
\hline Sex (Female) & $476(48.9)$ & $361(53.7)$ & $40(55.6)$ \\
\hline Education (none/primary) & $291(29.9)$ & $237(35.3)^{*}$ & $30(41.7)^{*}$ \\
\hline Married & $719(73.8)$ & $438(65.2)^{* *}$ & $39(54.2)^{* *}$ \\
\hline Rx medication exposure & $766(78.6)$ & $584(86.9)^{* *}$ & $71(98.6)^{* *}$ \\
\hline No. of drugs (Mean, SD) & $2.53(2.28)$ & $3.69(2.74)^{* *}$ & $5.46(2.89)^{* *}$ \\
\hline No. of chronic diseases (Mean, SD) & $1.93(1.37)$ & $2.39(1.57)^{* *}$ & $3.60(1.67)^{* *}$ \\
\hline Polypharmacy ( $\geq 5$ of drugs) & $176(18.1)$ & $236(35.1)^{* *}$ & $39(54.2)^{* *}$ \\
\hline IADL disability $(\geq \mathbf{1})$ & $13(1.3)$ & $26(3.9)^{* *}$ & $10(13.9)^{* *}$ \\
\hline ADL disability ( $\geq \mathbf{1})$ & $45(4.6)$ & $89(13.2)^{* *}$ & $29(40.3)^{* *}$ \\
\hline Global Cognitive Function (Mean MMSE score, SD) & $28.41(1.77)$ & $28.00(2.17)^{* *}$ & $27.08(2.66)^{* *}$ \\
\hline Depression (CES-D $\geq 16$ ) & $26(2.7)$ & $62(9.5)^{* *}$ & $21(29.6) * *$ \\
\hline Anxiety (HADS A $\geq 11$ ) & $50(5.5)$ & $66(10.9) * *$ & $10(17.2)^{* *}$ \\
\hline
\end{tabular}

I/ADL - Instrumental/Activities of Daily Living.

451 MMSE - Mini-Mental State Examination.

CES-D - Center for Epidemiological Studies -Depression scale.

HADS-A - Hospital Anxiety and Depression Scale -Anxiety schedule.

${ }^{*} \mathrm{p}<0.05,{ }^{* *} \mathrm{p}<0.001$ 
458

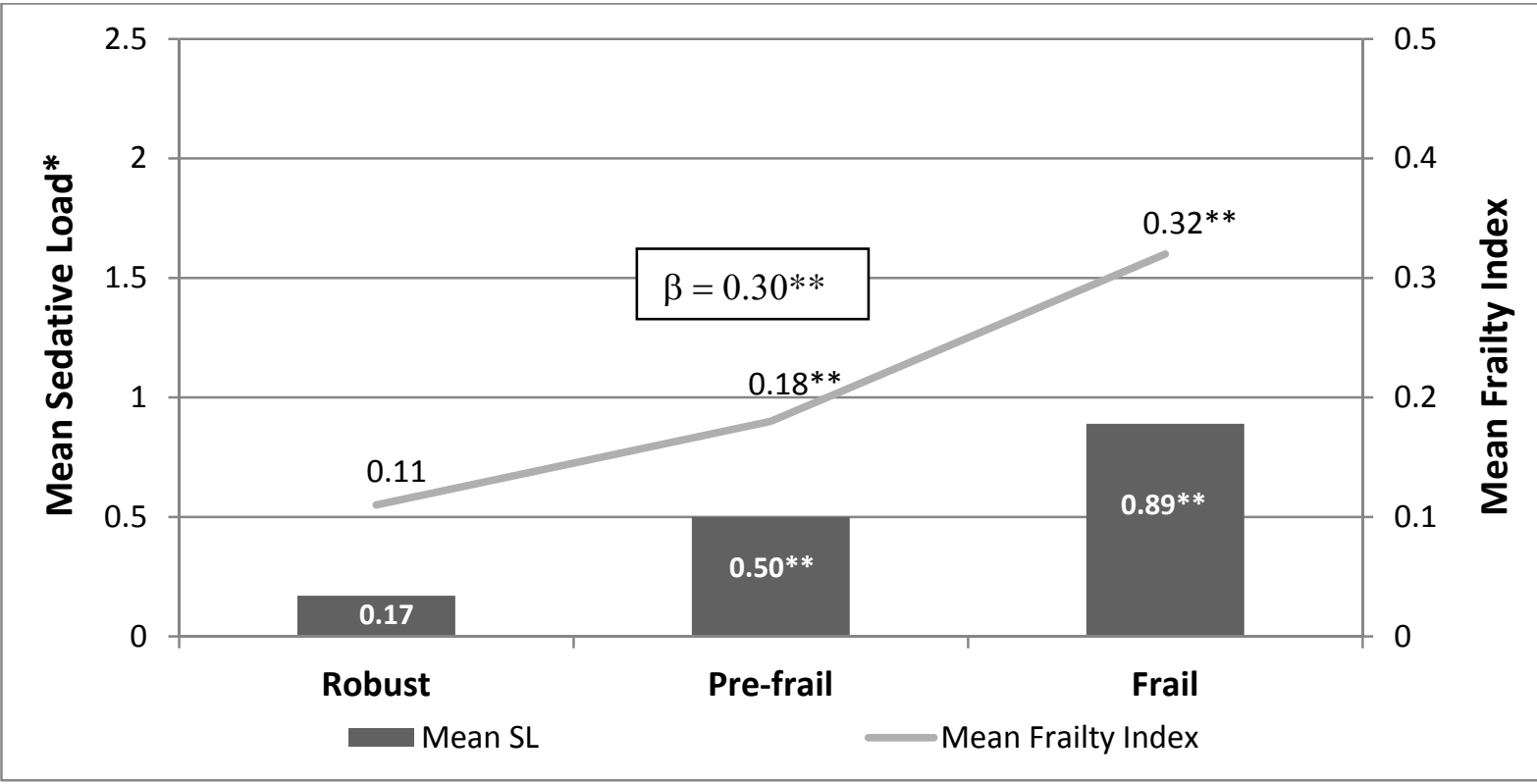

459 Figure 1. Unadjusted mean sedative load (SL) score was associated with prefrailty, frailty and frailty index score (FI) among participants aged $65+$ years $(n=1,718)$. ${ }^{* *} \mathrm{p}<0.001$

462 
496

497

498

Appendix I. Adjusted model of association between the modified sedative load (SL) score and frailty phenotype status $(n=1,718)$.

\begin{tabular}{|c|c|c|c|c|c|}
\hline \multirow[t]{2}{*}{ Variable } & \multirow[t]{2}{*}{ Category } & \multicolumn{2}{|l|}{ Prefrail } & \multicolumn{2}{|l|}{ Frail } \\
\hline & & $\begin{array}{c}\text { Adjusted OR } \\
{[95 \% \mathrm{Cl}]}\end{array}$ & $\begin{array}{c}\mathrm{p}- \\
\text { value }\end{array}$ & $\begin{array}{c}\text { Adjusted OR } \\
{[95 \% \mathrm{Cl}]}\end{array}$ & $\begin{array}{c}\mathrm{p}- \\
\text { value }\end{array}$ \\
\hline Sedative load (SL) score & [continuous variable] & $1.31(1.14-1.51)$ & $\leq 0.001$ & $1.43(1.08-1.90)$ & 0.014 \\
\hline Age (years) & [continuous variable] & $1.10(1.08-1.13)$ & $\leq 0.001$ & $1.29(1.21-1.37)$ & $\leq 0.001$ \\
\hline Depression & [continuous variable] & $1.08(1.05-1.10)$ & $\leq 0.001$ & $1.17(1.11-1.24)$ & $\leq 0.001$ \\
\hline Cognitive impairment & [continuous variable] & $0.90(0.84-0.96)$ & $\leq 0.001$ & $0.85(0.74-0.97)$ & 0.020 \\
\hline \multirow[t]{2}{*}{ Sex } & Male & 1 & & 1 & \\
\hline & Female & $1.16(0.91-1.49)$ & 0.229 & $0.96(0.49-1.86)$ & 0.901 \\
\hline \multirow[t]{2}{*}{ Education } & Secondary or higher & 1 & & 1 & \\
\hline & None/Primary & $0.84(0.65-1.08)$ & 0.173 & $0.63(0.31-1.27)$ & 0.197 \\
\hline \multirow[t]{2}{*}{ CVD } & No & 1 & & 1 & \\
\hline & Yes & $1.07(0.85-1.35)$ & 0.577 & $1.67(0.77-3.60)$ & 0.192 \\
\hline \multirow[t]{2}{*}{ Stroke } & No & 1 & & 1 & \\
\hline & Yes & $2.83(1.16-6.88)$ & 0.022 & $7.22(1.89-27.58)$ & 0.004 \\
\hline \multirow[t]{2}{*}{ Diabetes } & No & 1 & & 1 & \\
\hline & Yes & $2.07(1.38-3.11)$ & $\leq 0.001$ & $1.95(0.77-4.95)$ & 0.159 \\
\hline \multirow[t]{2}{*}{ Arthritis } & No & 1 & & 1 & \\
\hline & Yes & $1.20(0.94-1.53)$ & 0.150 & $2.05(1.04-4.03)$ & 0.037 \\
\hline \multirow[t]{2}{*}{ COPD/asthma } & No & 1 & & 1 & \\
\hline & Yes & $0.94(0.67-1.34)$ & 0.749 & $1.32(0.60-2.91)$ & 0.490 \\
\hline \multirow[t]{3}{*}{ Smoking } & Never & 1 & & 1 & \\
\hline & Current smoker & $1.45(0.96-2.19)$ & 0.076 & $3.84(1.40-10.55)$ & 0.009 \\
\hline & Past smoker & $1.09(0.85-1.40)$ & 0.506 & $1.32(0.63-2.76)$ & 0.464 \\
\hline \multirow[t]{2}{*}{ Alcohol consumption } & No & 1 & & 1 & \\
\hline & Yes & $0.77(0.60-0.99)$ & 0.044 & $0.82(0.41-1.64)$ & 0.576 \\
\hline \multirow[t]{2}{*}{$\mathrm{BMI}<18.5$ and $>30$ ) } & No & 1 & & 1 & \\
\hline & Yes & $1.32(1.03-1.69)$ & 0.029 & $1.40(0.70-2.82)$ & 0.344 \\
\hline \multirow[t]{3}{*}{ Disability ADL } & None & 1 & & 1 & \\
\hline & $\geq 1 \mathrm{ADL}$ & $2.23(1.44-3.46)$ & $\leq 0.001$ & $4.14(1.86-9.21)$ & $\leq 0.001$ \\
\hline & $\geq 1$ IADL & $2.15(0.99-4.64)$ & 0.052 & $7.07(2.12-23.55)$ & 0.001 \\
\hline \multirow[t]{2}{*}{ Self-rated health } & $\begin{array}{l}\text { Excellent/Very } \\
\text { good/Good }\end{array}$ & 1 & & 1 & \\
\hline & Fair/Poor & $2.54(1.63-3.94)$ & $\leq 0.001$ & $11.90(5.52-25.66)$ & $\leq 0.001$ \\
\hline \multirow[t]{2}{*}{ Loneliness } & None of the time & 1 & & 1 & \\
\hline & Most of all of the time & $0.86(0.50-1.47)$ & 0.578 & $0.79(0.28-2.21)$ & 0.658 \\
\hline
\end{tabular}


504 Appendix 2. Adjusted model of association between the original sedative load (SL) score 505 and frailty phenotype status $(n=1,718)$.

\begin{tabular}{|c|c|c|c|c|c|}
\hline \multirow[t]{2}{*}{ Variable } & \multirow[t]{2}{*}{ Category } & \multicolumn{2}{|l|}{ Prefrail } & \multicolumn{2}{|l|}{ Frail } \\
\hline & & $\begin{array}{c}\text { Adjusted OR } \\
{[95 \% \mathrm{Cl}]}\end{array}$ & $\begin{array}{c}\mathrm{p}- \\
\text { value }\end{array}$ & $\begin{array}{c}\text { Adjusted OR }[95 \% \\
\mathrm{Cl}]\end{array}$ & $\begin{array}{c}p- \\
\text { value }\end{array}$ \\
\hline Sedative load score & [continuous variable] & $1.35(1.16-1.56)$ & $\leq 0.001$ & $1.49(1.10-2.01)$ & 0,010 \\
\hline Age (years) & [continuous variable] & $1.10(1.08-1.13)$ & $\leq 0.001$ & $1.29(1.21-1.37)$ & $\leq 0.001$ \\
\hline Depression & [continuous variable] & $1.08(1.05-1.10)$ & $\leq 0.001$ & $1.17(1.11-1.23)$ & $\leq 0.001$ \\
\hline Cognitive impairment & [continuous variable] & $0.90(0.84-0.96)$ & $\leq 0.001$ & $0.85(0.74-0.98)$ & 0,021 \\
\hline \multirow[t]{2}{*}{ Sex } & Male & 1 & & 1 & \\
\hline & Female & $1.16(0.91-1.48)$ & 0,242 & $0.96(0.49-1.86)$ & 0,891 \\
\hline \multirow[t]{2}{*}{ Education } & Secondary or higher & 1 & & 1 & \\
\hline & None/Primary & $0.84(0.65-1.09)$ & 0,181 & $0.63(0.31-1.28)$ & 0,202 \\
\hline \multirow[t]{2}{*}{ CVD } & No & 1 & & 1 & \\
\hline & Yes & $1.07(0.85-1.36)$ & 0,558 & $1.68(0.78-3.62)$ & 0,188 \\
\hline \multirow[t]{2}{*}{ Stroke } & No & 1 & & 1 & \\
\hline & Yes & $2.83(1.16-6.89)$ & 0,022 & $7.20(1.88-27.54)$ & 0,004 \\
\hline \multirow[t]{2}{*}{ Diabetes } & No & 1 & & 1 & \\
\hline & Yes & $2.09(1.39-3.14)$ & $\leq 0.001$ & $1.98(0.78-5.01)$ & 0,152 \\
\hline \multirow[t]{2}{*}{ Arthritis } & No & 1 & & 1 & \\
\hline & Yes & $1.20(0.94-1.54)$ & 0,138 & $2.06(1.05-4.05)$ & 0,035 \\
\hline \multirow[t]{2}{*}{ COPD/asthma } & No & 1 & & 1 & \\
\hline & Yes & $0.95(0.67-1.35)$ & 0,770 & $1.34(0.61-2.94)$ & 0,474 \\
\hline \multirow[t]{3}{*}{ Smoking } & Never & 1 & & 1 & \\
\hline & Current smoker & $1.45(0.96-2.18)$ & 0,079 & $3.81(1.39-10.45)$ & 0,010 \\
\hline & Past smoker & $1.09(0.84-1.39)$ & 0,524 & $1.30(0.62-2.73)$ & 0,486 \\
\hline \multirow[t]{2}{*}{ Alcohol consumption } & No & 1 & & 1 & \\
\hline & Yes & $0.78(0.60-1.00)$ & 0,051 & $0.83(0.42-1.66)$ & 0,602 \\
\hline \multirow[t]{2}{*}{$\mathrm{BMI}<18.5$ and $>30$ ) } & No & 1 & & 1 & \\
\hline & Yes & $1.32(1.03-1.69)$ & 0,027 & $1.41(0.70-2.84)$ & 0,334 \\
\hline \multirow[t]{3}{*}{ Disability ADL } & None & 1 & & 1 & \\
\hline & $\geq 1 \mathrm{ADL}$ & $2.21(1.43-3.44)$ & $\leq 0.001$ & $4.10(1.84-9.12)$ & $\leq 0.001$ \\
\hline & $\geq 1 \mathrm{IADL}$ & $2.16(1.00-4.67)$ & 0,050 & $7.08(2.12-23.62)$ & $\leq 0.001$ \\
\hline \multirow[t]{2}{*}{ Self-rated health } & $\begin{array}{l}\text { Excellent\Very } \\
\text { good } \backslash \text { Good }\end{array}$ & 1 & & 1 & \\
\hline & Fair\Poor & $2.53(1.63-3.93)$ & $\leq 0.001$ & $11.88(5.51-25.62)$ & $\leq 0.001$ \\
\hline \multirow[t]{2}{*}{ Loneliness } & None of the time & 1 & & 1 & \\
\hline & All or most of the time & $0.87(0.51-1.50)$ & 0,624 & $0.81(0.29-2.26)$ & 0,690 \\
\hline
\end{tabular}

